\title{
UN SERMÓN EDITADO POR EL INCA GARCILASO
}

La Historia general del Perú fué obra póstuma ${ }^{1}$, los Comentarios reales se imprimieron en 1609 . Un pequeño folleto, ni siquiera original, un sermón predicado en Málaga por un fraile franciscano, iba a ser la última publicación hecha en vida por el Inca historiador. Ningún especialista había tenido noticia de este sermonario. Sin embargo, en 1900, Valdenebro y Cisneros lo registraba en La imprenta en Córdoba, indicando que un ejemplar se conservaba en la Biblioteca Provincial de Sevilla. Allí existe hasta hoy, encuadernado en un tomo de Varios, núm. 11 3559 , fols. 454 y sigs. $^{2}$ El opúsculo se titula Sermón que predicó el Reverendo P. F. Alonso Bernardino, Predicador de la Orden del Seráfico P. san Francisco, en la Ciudad de Málaga, en la fiesta del bienauenturado san Ilefonso, Arcobispo de Toledo, primado de las Españas. El qual Sermón se imprime a pedimento del Yndio Garcilaso de la Vega, para gloria y honra de Dios nuestro Señor, y de la Virgen Maria su Madre. En Córdoua. Por Francisco de Cea ${ }^{3}$, Año de 1612 (en $4^{\circ}, 12$ hojas foliadas).

Es la segunda vez que el Inca se presenta como "el Indio" en una portada; la primera en La traduzión del indio de los tres Diá-

1 Aurelio Miró-Quesada (El Inca Garcilaso, Lima, 1947, pág. 297) ha visto un ejemplar de la Historia general del Perí fechado en 1616. Aunque a ciencia cierta no puede afirmarse que se trate de una simple errata, el hecho es que la segunda parte sólo aparece en 1617 . Por lo demás, es probable que ese ejemplar de 1616 fuese también póstumo, pues el Inca murió en el nes de abril.

* Cf. José María de Valdenebro y Cisneros, La imprenta en Córdoba. Ensayo bibliográfico, Madrid, 1900, págs. 52-53. A ello hicimos referencia en "La biblioteca del Inca”, NRFF, II, 1948, pág. 263. Recientemente Aurflio MiróQuesada ha publicado el opúsculo del Inca en $M d S$, VII, núm. 2o, págs. 69 y sigs., valiéndose de una copia facilitada por el Dr. Guillermo Céspedes; agradecemos al Dr. Miró-Quesada su mención de un estudio inédito sobre dicho opúsculo, que presentamos en 1949 como apéndice a una tesis universitaria Ese estudio, puesto al día y un tanto modificado, es el mismo que ahora ofrecemos.

" Única obra que d Inca cncargó a cste impresor, pese a que parece haberle teniclo algún afecto. En un menorial testamentario expresa que es su voluntad "perdonar ... a Franciseo de Geal, impresor de libros, lo que pareciere deverme por una cédula que contra de tengo, i mando no se le pida, antes se le entregue la dicha cédula, i esto por le hazer bien i limosna" (apud José dE LA 'Torre: y DFL CFrro, El Inca Garcilaso de la Vega. Nueva documentación, Madrid, 1935, 
logos de Amor; luego, en la Florida y en los Comentarios, como "el Inca". Siempre, pues, de un modo o de otro, se le ve afanoso por subrayar su condición de americano, o por decir mejor, de hombre exótico pero incorporado a las letras españolas y al humanismo europeo. No se olvide que en Garcilaso, primer gran escritor mestizo, apunta ya claramente un orgullo patriótico de cuzqueño, peruano y americano ${ }^{4}$. De ello también da fe el presente folleto.

No carece por cierto de interés biográfico. En primer lugar, porque es una nueva prueba, y muy significativa, del espíritu religioso del Inca, clérigo entonces, ya viejo y a punto de morir. Luego, porque el padre Bernardino era natural de Montilla, ciudad en que transcurrió gran parte de la vida española de Garcilaso $^{5}$ : a los veinte años de haberla abandonado da muestras, como veremos, de vivo afecto por esta pequeña ciudad, tan grata al solitario y noble mestizo. Y sobre todo porque el opúsculo va "dirigido a don Alonso Fernández de Córdoua y Figueroa Marqués de Priego, Señor de la casa de Aguilar". Este buen marqués, deudo del Inca, era también su deudor, y de una fuerte cantidad de dinero. Al parecer, la dedicatoria no pretende alcanzar protección, como era general en la época, sino más bien trata, con maneras sumamente cordiales, de asegurar el pago de largos miles de maravedís.

Las relaciones del Inca con los Marqueses de Priego no fueron siempre cordiales, aunque en un principio sí: el marqués-consorte don Alonso Fernández de Córdoba, abuelo del de la dedicatoria, fué gran amigo de don Alonso de Vargas, tío carnal de Garcilaso (los Priego eran parientes de los Vargas, algo lejanos). En Montilla, cabeza de los estados de Priego, pasó Alonso de Vargas los últimos años de su vida, y dejó en herencia a sus sobrinos dos valiosos censos $^{6}$, impuestos sobre los bienes de los Marqueses de Priego. Desde la muerte de su tío, en 1570 , hasta fines de 1591 , el Inca vivió en Montilla: allí tradujo a León Hebreo y escribió gran parte de la Florida. En la Genealogia de Garci Pérez de Vargas habla Garcilaso con gran cariño de la marquesa doña Catalina y también de la abuela de ésta, del mísmo nombre, a quien debió conocer ya muy anciana.

pág. 212). Tal afecto y dadivosidad por Cea bien pudo deberse a que fuć éste cl impresor cordobés en cuya casa encontró una crónica que luego usó en la Florida, obra del soldado Coles (cf. Florida, Proemio al lector).

"Cif. "El Inca español” en Américas, mayo de 1953, passim.

5 Cif. Raúl Porras Barrfnfchfa, "Nuevos documentos sobre el Inca Garcilaso”, Documenta, II, 1949-50, págs. 593 y sigs.

"A juzgar por protocolos inćditos que se conservan en el Archivo del Cuzco, parece que Garcilaso fué ençomendado descle el Perú a su tío carnal Alonso de Vargas, el cual, por cierto, fué el único de sus parientes españoles que lo acogió debidamente; y no sólo lo acogió, sino que lo relacionó con los Priego, según todos los indicios. 
Pero años más tarde, los censos, que eran el todo en su modesta fortuna, resultaban prácticamente incobrables por la poca formalidad del marqués don Pedro, sucesor del título ${ }^{7}$. En 1591 le debía 93,159 maravedís, 166,070 en 1593, y en agosto de 1599 la deuda llegaba a 1,16o ducados. Y aunque llegó a pagar algo, a la muerte de don Pedro la obligación pasaba con mucho de los 30o,ooo maravedís. Es la época en que Garcilaso termina la Florida y escribe los Comentarios, en donde más de una vez se queja de sus penurias económicas. El nuevo Marqués - don Alonso también, como su abuelotampoco resultó buen pagador, hasta que en 1608 la situación parece haber mejorado y el Marqués se muestra asequible, pues amortiza parte de la deuda.

Pocos años después decide el Inca publicar el sermón del padre Bernardino (la censura está fechada en Córdoba, el 26 de agosto de 1611). Mejoradas las relaciones con Priego, el Inca decide dedicarle el sermonario. Las armas del Marqués figuran en el folleto, y en la dedicatoria, con fecha en Córdoba, 3o de enero de 1612, Garcilaso se dirige con respeto y cordialidad a su distinguido pariente:

Vn amigo mío, Señor Ilustríssimo y Excelentíssimo, sabiendo que yo auía de receuir mucho contento con la dádiua, me hizo gracia de vnos Sermones, que de diuersas partes auía recogido, porque es curioso de semejantes cosas: Entre los quales hallé vno del Padre Fray Alonso Bernardino, Predicador de la orden del Seráfico Padre san Francisco, con el qual holgué mucho por ser el autor natural de Montilla, hijo, nieto y decendiente de vassallos y criados de la casa de $\mathrm{V}$. Exc. que parte dellos murieron en sierra Bermeja con Don Alonso de Aguilar mi señors, y otra parte (por auerlo mandado su Exc.) se retiraron con mi señor don Pedro Fernández de Córdoua y Aguilar primer marqués de Priego ${ }^{9}$. Aumentóme el contento ser el sermón en loor y alabança del bienauenturado san Ilefonso Arçobispo de Toledo, que fué Español, y tan deuoto de Nuestra Señora la Virgen María, como lo muestran sus obras tan heroycas ${ }^{10}$, y la remu-

7 Para la historia de estos censos, of. De i a Torre y dei Crrro, op. cil., passim, y Miró-Quesada, op. cit., cap. vi.

8 Alude aquí al célebre hecho de armas en que murió heroicamente don Alonso de Aguilar, hermano del Gran Capitán. Fué en la derrota de Calaví, Sierra Bermeja, el año 1501.

- El Inca combatió después, en las guerras civiles de Granada, dentro de la mesnada que envió el mismo marqués don Pedro. Cf. Porras Barrenkchea, loc. rit.

to Nueva prueba de la devoción mariana que tenía el Inca Garcilaso. Devoción que importa de manera especial para un estudio de sus ideas religiosas, sobre todo si se revisa lo que al Inca le tocó del pensamiento erasmista. Sobre este punto ha incidido Luis Arocisa, en El Inca Garcilaso y el humanismo renacentista, Buenos Aires, 1949, cap. III. 
neración dellas por mano de la misma Virgen, y Madre de Dios. A este mi contento, y regocijo no aumentó poco auer cabido a $\mathrm{V}$. Exc. en suerte el nombre deste diuino varón para animarme a dedicarle este sermón, porque por las mismas causas V. Exc. recebirá con él mucho gusto, assí por ser tan deuoto de cosas tan santas, como por el nombre del santo, que es el de V. Exc. y por ser la obra de hijos de criados de vuestra casa, a los quales V. Exc. professa fauorecer, y amparar como quien es. Por todo lo qual suplico a V. Exc. perdone mi atreuimiento, que como obligado a vuestro seruicio, y a los naturales de vuestro estado, particularmente a los de Montilla por auer residido yo largo tiempo en ella me animé a ofrecer a $\mathrm{V}$. Exc. este pequeño seruicio: pequeño en cantidad, pero muy grande en calidad y santidad, \&c. Nuestro Señor la persona, y casa de V. Exc. guarde con aumento de mayores estados, como los seruidores de V. Exc. lo desseamos, Amén. De Córdoua 30 de enero de 1612.

$$
\text { [fol. } \left.4 \mathrm{r}^{\mathrm{o}} \mathrm{y} \mathrm{v}^{\mathrm{o}}\right] \text {. }
$$

El resultado de la dedicatoria no pudo ser mejor. En septiembre de 1612 vemos a Garcilaso gestionar la compra de la Capilla de las Ánimas de la catedral de Córdoba, donde hoy yace enterrado. Es indudable que al decidirse a efectuar este fuerte gasto, que le llevaba más de lo que entonces tenía, Garcilaso se hallaba seguro de cobrarle a Priego. Y así fué: el 28 de marzo de 1613 el Inca otorgó una escritura en la que daba por recibidos los 433,928 maravedís que le debía el Marqués hasta diciembre del año anterior. ¡Curiosa actitud de Garcilaso! Impaciente por adquirir sepultura en lugar glorioso, se anticipa a tener siquiera el dinero en sus manos, e inicia los tratos, para gastar al fin en su tumba lo mejor de su hacienda. ¿Qué ambición tan hispánica de honra vemos latir aquí! Porque el hijo del Nuevo Mundo que en la portada del folleto se pregona indio, en la dedicatoria se muestra alegre de recordar que San Ildefonso es español; y el mismo hombre que vive de la nostalgia de su Cuzco perdido, muere ansioso de enterrarse en la vieja mezquita y santa iglesia catedral cordobesa, sepulcro honroso si los hay ${ }^{11}$.

Tres libros del Inca Garcilaso fueron dedicados a reyes: la traducción de los Dialoghi d'Amore a Felipe II y a Maximiliano de Austria; la Florida al Duque de Braganza ${ }^{12}$, los Comentarios reales a la duquesa Catalina, también reina, prácticamente, de Portugal. Su obra póstuma, la Historia general del Perú, segunda parte de los

11 Cf. "La idea de la honra en el Inca Garcilaso", publicado primero en $C u A$, noviembre-diciembre de 1951 , y luego reproducido, con erratas enmendadas, en Panorama, I, núm. 1 .

${ }^{12}$ La Florida estuvo dedicada en un principio a Garci Pérez de Vargas, cabeza de los descendientes del glorioso soldado de la toma de Sevilla. Cf. "Dos notas sobre el Inca Garcilaso", NRFH, III, 1949, pág. 286, y nota 26. 
Comentarios, no será para príncipe de este mundo, sino "dirigida a la limpíssima Virgen María", de quien era gran devoto. Y ahora que dedica un impreso ya no a rey sino a noble poderoso, no será para alcanzar favores, sino tan sólo para mejorar una relación amistosa y obtener, así, el pago de una deuda. Por entonces, cuando ya se tenía por hombre "despedido de este mundo", poco le importarían ya los mecenas.

Rasgo revelador: halagar para cobrar, hacer honra al poderoso para lograr no su largueza, sino su justicia. Algo que condice muy bien con el espíritu tímido del Inca, y que confirma nuevamente las ideas de Porras Barrenechea sobre el carácter del cronista ${ }^{13}$. Junto a la timidez, aparece la cortesía: cortesía de español, de criollo y de indio. Amigo de la etiqueta y las elegantes razones, en la dedicatoria a don Alonso, lo mismo que en otros casos, lo vemos hacer amplio uso de las fórmulas de acatamiento y las mil zalamerías que entonces estilaban los españoles, y que los indianos solían exagerar ${ }^{14}$.

$Y$ en fin, siempre vemos a Garcilaso encariñado con las cosas, personas y hechos que tienen que ver con su vida. Alma en frecuente zozobra, preocupada por sí misma, inclinada a hablar de temas que le eran íntimos, manifiesta aquí también esta condición. Garcilaso publica el sermón, entre otras razones, porque el padre Bernardino había nacido en Montilla - pueblo muy querido de Garcilaso- y porque era pariente, creemos, de buenos amigos suyos. No parece que el Inca hubiese conocido al predicador franciscano, pues nada dice de él en la dedicatoria; pero es significativo que uno de los mejores amigos de Garcilaso lleve el mismo apellido: Cristóbal de Luque Bernardino, presbítero, vecino de Montilla ${ }^{1.5}$. Garcilaso, como patrón de la capellanía que fundó su tío en esa ciudad, en ${ }_{1598}$ lo nombró capellán. Años más tarde, en su testamento, le deja de por vida ese patronazgo. Pero es más: el padre Luque Bernardino era el encargado de los negocios de Garcilaso en Montilla, y como tal tuvo que lidiar por muchísimos años con los Marqueses de Priego. Es curioso que el sermonario dedicado al marqués don Alonso sea

13 Porras Barrenfchfa, El Inca Garcilaso de la Vega, Lima, 1946, págs. $7-8,23-24$.

${ }^{14}$ Cf. La transformación social del conquistador, México, 1953, cap. Ix.

1" Hay un Lorenzo de Luque, presbítero, vecino de Montilla y quizá pariente de Cristóbal, testigo del testamento de don Alonso de Vargas (otorgado en ese lugar, en 1570 ); la relación de otro Luque con el tío del Inca parece indicar que la amistad de Garcilaso con el padre Cristóbal tenía viejos antecedentes familiares: Esta amistad no sólo se aprecia en la confianza del Inca al hacerle su administrador, sino que también se muestra en el interés de Luque por servir a Garcilaso: cuando éste se traslada de Montilla a Córdoba, Luque Bernardino lo acompaña. Y así lo vemos, siempre "vecino de Montilla", firmando como testigo un poder otorgado por el Inca (cf. DE LA Torkf. y DEI. Carro, op. cit., págs. 8 y 10 , y passim). 
al parecer obra de un pariente del eterno cobrador de las eternas deudas. La amistad con Luque Bernardino debió influir en el gusto del Inca por este sermón; y no sería de extrañar que el clérigo Luque fuese el amigo que le regaló estos sermones ${ }^{16}$.

Dijimos que, a pesar de que Valdenebro lo consigna, este opúsculo ha pasado inadvertido por muchos años para los estudiosos. También para José de la Torre y del Cerro, cuya erudita Nueva documentación trata casi exclusivamente de la vida cordobesa de Garcilaso. Cosa muy explicable, porque el mismo silencio guarda el Inca acerca de esta pequeña obra, y no por falta de oportunidad: en la Historia general, lib VII, cap. xxx, cuenta que obsequió al franciscano Luis Jerónimo de Oré, criollo del Perú, "con siete libros: los tres fueron de la Florida y los cuatro de nuestros Comentarios, de que Su Paternidad se dió por muy bien servido". Esto ocurrió "al principio del año de mil y seiscientos y doze", esto es, por el mismo tiempo en que debió aparecer el folleto (hacia febrero del mismo año). Oré, como Bernardino, era franciscano; y aun en el supuesto de que visitase al Inca en enero, como es posible, debieron charlar de este sermón, cuya publicación se gestionaba desde agosto del año anterior.

No sólo guarda silencio el Inca acerca de esta obrita. En el inventario de su biblioteca, donde notario y albaceas cuidan de anotar cuadernillos y pequeñas publicaciones, donde se registran "quinientos libros, poco más o menos, en papel de la Primera parte de los Comentarios Reales", algún volumen de los Diálogos de amor y "quatro libros de la Florida"17, no se toma en cuenta un solo ejemplar de este opúsculo, editado tres años después de los Comentarios. Si el Inca y sus amigos no paraban mientes en este cuadernillo, es de excusar que los eruditos de tres siglos después, hasta días muy recientes, no lo hayan sacado del olvido.

Universidad Mayor de San Marcos,

José DURAND lima.

1" Otro escrito de carácter oratorio que publica Garcilaso tiene también relación con su vida: es un elogio póstumo de su padre; se halla recogido en la Historia general, lib. VIII, cap. XII.

17 Cf. "La biblioteca del Inca", art. cit., pág. 262. 